\title{
PENGEMBANGAN GAME RPG 2D LEGENDA DESA TRUNYAN
}

\author{
Made Agus Panji Sujaya', I Gede Mahendra Darmawiguna², Made Windu Antara \\ $\operatorname{Kesiman}^{3}$ \\ 1,3 Prodi Pendidikan Teknik Informatika Jurusan Teknik Informatika Fakultas Teknik dan Kejuruan Universitas \\ Pendidikan Ganesha, Jln. Udayana No. 11 Singaraja 81116 INDONESIA \\ 2 Prodi Sistem Informasi Jurusan Teknik Informatika Fakultas Teknik dan Kejuruan Universitas Pendidikan Ganesha, \\ Jln. Udayana No. 11 Singaraja 81116 INDONESIA
}

\begin{abstract}
Abstrak
Cerita rakyat Legenda Desa Trunyan kurang dikenal oleh masyarakat Indonesia khususnya masyarakat Bali, ini terjadi karena masyarakat Bali hanya mengenal cerita

Kata Kunci:

Cerita Rakyat, Legenda Desa Trunyan, Gim rakyat yang terkenal saja. Jika dibiarkan maka cerita rakyat Legenda Desa Trunyan akan dilupakan dan meruntuhkan semua potensi ada padanya. Gim Trunyan dikembangkan sebagai solusi dari permasalahan tersebut. Penelitian ini bertujuan untuk melestarikan cerita rakyat Legenda Desa Trunyan menggunakan media gim yang melibatkan interaksi pemain di dalamnya dan mengenali respon masyarakat terhadap hasil pengembangan dari gim Trunyan. Game RPG 2D Legenda Desa Trunyan dikembangkan dengan metode Penelitian dan Pengembangan, dengan model Game Development Life Cycle yang terdiri atas Initiation, pre-production, production, testing, beta, dan release. Gim ini diharapkan dapat memperkenalkan cerita rakyat Legenda Desa Trunyan kepada masyarakat luas sehingga kelestariannya tetap terjaga. Terdapat 4 kali pengujian, yakni pengujian blackbox, pengujian ahli isi, pengujian ahli media, dan pengujian respon pengguna. Hasil pengujian blackbox menunjukkan semua mechanics yang dirumuskan berfungsi dengan baik, diikuti oleh pengujian ahli isi yang menunjukkan gim Trunyan memiliki tingkat validasi sangat tinggi dengan koefisien validitas sebesar 1.00, kemudian diuji oleh ahli media dengan hasil tingkat validasi sangat tinggi dengan koefisien validitas sebesar 1.00, yang terakhir pengujian respon pengguna dengan persentase $93 \%$ yang termasuk dalam kategori "Sangat Baik"
\end{abstract}

\begin{abstract}
Most Indonesian people, specifically Balinese people didn't know about The Legend of Trunyan Village Folklore, this happened because Balinese People only know the wellknown folklore. If remains happened, The Legend of Trunyan Village will be forgotten, to get rid of this problem, the game entitled "Trunyan" is developed as a solution to this problem. This study aims to preserve The Legend of Trunyan Village folklore using game media which involves player interaction and recognizes the community's response to the development result of the game. The game was developed using Research and Development method, with the Game Development Life Cycle model consisting of initiation, pre-production, production, testing, beta, and release. This game is expected to introduce The Legend of Trunyan Village folklore to the wider community so that its sustainability is maintained. There are 4 times of testing, first is BlackBox testing, content expert testing, game developer expert testing and user response testing. The result of BlackBox testing shows that all of the mechanics formulated are functioning well, followed by content expert testing which shows the game has a very high validation level with a validity coefficient of 1.00, then tested by game developer experts with a very high validation level with a validity of coefficient of 1.00, which the last test was the user response with a percentage of 93\% which was included in the "Very Good" category.
\end{abstract}

\section{PENDAHULUAN}

Teknologi yang berkembang dengan pesat memberikan perubahan yang signifikan dalam berbagai aspek kehidupan manusia, seperti contohnya perubahan dalam aspek pendidikan yang kini semakin mengedepankan teknologi dalam pelaksanaannya. Aspek pendidikan dalam lingkungan keluarga juga tak luput dari pengaruh teknologi. Jika kita berkaca pada masa lalu yang masih serba tradisional, moral dan etika generasi muda dipupuk melalui karya sastra klasik, sedangkan dewasa ini begitu banyak produk teknologi multimedia yang menggantikan pewarisan moral dan etika generasi muda. Hal ini menggantikan 
karya sastra klasik yang jika dibiarkan akan memusnahkan eksistensi karya sastra klasik tersebut, jika kita mengambil kasus yang akan terjadi pada masyarakat bali, tidak ada lagi tradisi orang tua yang melantunkan sekar alit dan pupuh (puisi) yang sarat akan pesan moral seperti yang dikatakan oleh Kotaniartha pada jurnalnya mengenai sekar alit merupakan karya sastra yang sarat akan makna menghargai kehidupan, kemerdekaan, tanggung jawab, keadilan, kejujuran, toleransi, dan nilai-nilai moral lainnya (Kotaniartha \& Wijayanti, 2019).

Karya sastra klasik lain yang kerap menjadi media tradisional dalam memupuk nilai moral dan nilainilai berbudi luhur adalah cerita rakyat yang kerap diceritakan sebagai dongeng pengantar tidur (Gusal. La Ode, 2015). Di bali sendiri terdapat cerita rakyat yang terkenal seperti Asal Mula Selat Bali, Legenda Kebo Iwa, Jayaprana Layonsari, tak sedikit juga cerita yang kurang dikenal seperti legenda Desa Trunyan.

Legenda Desa Trunyan menceritakan perjalanan keempat bersaudara pangeran dan putri Kerajaan Surakarta menuju sumber bau harum misterius yang belakangan diketahui berasal dari pohon Taru Menyan yang tumbuh di tanah Bali. Cerita rakyat Legenda Desa Trunyan ini kurang dikenal oleh masyarakat karena cerita ini tidak diceritakan oleh guru/orang tua, dan cerita ini sangat jarang dipublikasikan ke dalam bentuk buku atau media elektronik. Hasil survei terhadap 127 responden masyarakat daerah bali mengatakan bahwa sebanyak 73 responden tidak mengetahui Legenda Desa Trunyan. Survei lebih lanjut menyatakan bahwa 75 responden menjawab tidak tahu atau lupa tentang bagaimana responden bisa mengetahui cerita rakyat legenda desa trunyan, dan 24 responden menjawab mengetahuinya dari orang lain, 20 responden menjawab mengetahui dari internet, dan sisanya menjawab dari buku dan TV. Hal ini menunjukkan bahwa saarana pembuka wawasan mengenai cerita rakyat ini masih dipegang oleh cerita yang diwariskan turun temurun.

Cerita rakyat yang diwariskan secara turun temurun tidak luput dari kelemahan, sekalipun pernah menjadi sarana unggulan pada zamannya. Kelemahan itu yakni rawan terjadi distorsi informasi akibat interpretasi yang berbeda-beda oleh setiap orang yang membuat cerita rakyat asli menjadi tenggelam keasliannya. Sarana internet sebagai yang terbanyak nomer 2 pun memiliki kelemahan seperti pewarisan cerita rakyat secara lisan ditambah kelemahan lainnya yakni kurangnya interaksi yang dapat dilakukan audience yang berpengaruh pada persentasi informasi yang dapat diingat, seperti yang dikatakan Asmawati pada jurnalnya, terdapat beberapa jenis gaya belajar seperti auditorik, visual, dan kinestetik, gaya kinestetik yang mengkombinasikan interaksi fisik dan materi belajar (Asmawati et al., 2017) tidak dapat diakomodir jika sarana tidak interaktif.

Sarana interaktif lain dalam mewariskan cerita rakyat seperti drama juga dipandang kurang efektif karena memiliki kekurangan yakni terbatasnya jumlah pemain, dan penonton tidak melakukan apapun selain menonton. Dipandang dari segi finansial dirasa cukup berat jika dilakukan secara rutin/terusmenerus, terlebih jika pementasan drama tersebut dilakukan secara gratis seperti pementasan oleh kelompok ekstrakurikuler sekolah, unit kegiatan mahasiswa, ataupun kelompok pembelajaran dalam kelas.

Oleh karena itu diperlukan sebuah sarana dimana semua orang dapat berpartisipasi secara interaktif, dapat dilakukan secara rutin tanpa mengkhawatirkan pengeluaran yang berlebihan. Jika kita masih berada di zaman sebelum globalisasi terjadi tentu akan terlihat tidak mungkin. Namun, sarana ini sangat mungkin untuk diimplementasikan dengan bantuan teknologi.

Budaya yang diperkenalkan secara interaktif dengan bantuan teknologi merupakan sebuah opsi yang berpotensi efektif untuk dilakukan, terlebih jiak menggunakan media yang tepat dan populer untuk pelaksanaannya. Hasil survei yang dilakukan oleh Asosiasi Penyelenggara Jasa Internet Indonesia dalam kurun waktu 2019-2020 menunjukkan bahwa bermain gim sebagai produk teknologi menempati posisi ketiga sebagai alasan seseorang untuk menggunakan internet (APJII, 2020). Hal ini menginspirasi penulis untuk mengusulkan solusi berupa pengadaptasian Cerita Rakyat Legenda Desa Trunyan menjadi sebuah gim petualangan yang interaktif dan minim akan distorsi informasi yang berpotensi merusak keaslian Cerita Rakyat Legenda Desa Trunyan tersebut.

Solusi pengadaptasian Cerita Rakyat Legenda Desa Trunyan menjadi sebuah gim diperkuat dengan hasil survei yang menyatakan bahwa 123 dari 127 responden menyatakan tertarik jika Cerita Rakyat Legenda Desa Trunyan dikembangkan menjadi sebuah gim. Dalam perancangannya, gim akan beraliran role playing game agar sesuai dengan cerita rakyat yang merupakan petualngan. Aliran role playing game akan menempatkan pemain seolah-olah adalah tokoh utama dalam permainan tersebut (C \& Akbarsyah, 2013).

Selain untuk menghasilkan gim komputer yang beraliran role playing game dengan gaya 2D yang mengadopsi cerita rakyat Legenda Desa Trunyan, penelitian ini bertujuan untuk mengetahui bagaimana gim Trunyan dikembangkan dan mengetahui respon pengguna ketika memainkan gim tersebut, dan pelaksanaan penelitian ini memiliki beberapa manfaat yakni sebagai sarana perkenalan cerita rakyat baru yang dapat menambah wawasan generasi muda mengenai cerita rakyat di Indonesia yang beragam, dengan ini diharapkan cerita rakyat Legenda Desa Trunyan dapat dilestarikan dan tak terhapuskan oleh zaman. 


\section{A. Literature Review}

Pemanfaatan gim sebagai media alternatif selain media telah dilakukan oleh beberapa peneliti sebelumnya, sebagai contoh penelitian yang dilakukan oleh Sanjaya yang mengembangkan sebuah gim untuk platform Android yang memperkenalkan tradisi budaya Bali yang berjudul "Explore Bali". Penelitian ini berangkat dari peluang kepopuleran platform Android mengingat semakin menjamurnya pengguna android. Tradisi yang diperkenalkan dalam gim ini merupakan tradisi yang berasal dari beberapa daerah yang ada di Bali. Sanjaya mengembangkan gim ini dengan melalui beberapa tahapan yakni pengumpulan data, game design, pengujian sistem dan perancangan sistem. Terakhir saat pengujian menunjukkan bahwa pengetahuan pengguna mengenai tradisi budaya Bali bertambah menjadi 74\% dari persentase awal $67 \%$ (Sanjaya et al., 2016).

Penelitian lainnya dikembangkan oleh Meolbatak menilai bahwa dengan memperkenalkan budaya kepada anak sejak dini mampu menanamkan nilai keberagaman sehingga anak dapat menerima perbedaan yang akan ditemuinya di masa mendatang. Meolbatak mengembangkan gim yang mengenalkan budaya Dawan yang terdapat di Timor Tengah utara. Meolbatak melakukan penelitian dengan tahapan yang diawali dari analisis kebutuhan, pemodelan dan yang terakhir adalah implementasi. Hasil uji produk yang dilakukan mengatakan bahwa perancangan gim ini membantu anak dalam mengenal dan memahami budaya asli Dawan, sesuai dengan kuesioner uji coba yang disebarkan kepada peserta yang memberikan nilai sebanyak 78\% (Meolbatak et al., 2018).

Penelitian mengenai pengembangan gim RPG telah dilakukan sebelumnya, pemanfaatan gim sebagai media edukasi telah dilakukan oleh beberapa peneliti lain seperti contohnya penelitian yang dilakukan oleh Eldiana yang mengembangkan gim edukasi yang berjudul "COC" atau "Competition Of matemathiCs" dengan menggunakan perangkat lunak "RPG Maker MV". Berangkat dari permasalahan mengenai banyaknya respons negatif dari siswa terhadap mata pelajaran matematika khususnya pada materi KPK dimana sebagian besar siswa merasa bahwa pelajaran tersebut sangatlah sulit untuk dimengerti, Eldiana mengusung penelitian yang berjudul "Pengembangan Game "COC" RPG Maker MV Sebagai Media Pembelajaran Pada Materi KPK" dengan menggunakan model pengembangan ADDIE (Analysis, Design, Development, Implementation, and Evaluation). Produk gim yang telah selesai dikembangkan kemudian dilakukan uji coba kepraktisan dan hasilnya memperoleh nilai praktikalitas sebesar $82 \%$ ketika diuji oleh guru dan 76\% ketika diuji coba pada siswa (Eldiana \& Muliawati, 2019).

Dengan memanfaatkan gim sebagai media Edukasi dalam pembelajaran eksak, maka tak menutup peluang gim juga dapat dimanfaatkan sebagai media pengenalan cerita rakyat, seperti penelitian yang dilakukan oleh Uthami yang menghadapi permasalahan tentang berkurangnya kegiatan mewariskan cerita rakyat yang diakibatkan modernisasi dan globalisasi. Uthami berpendapat jika hal ini dibiarkan maka banyak cerita rakyat yang diwariskan secara turun temurun akan terlupakan begitu saja, salah satunya adalah cerita rakyat Bali I Bintang Lara. Dengan menggunakan model ADDIE, Uthami mengembangkan gim dengan judul I Bintang Lara untuk platform Android. Dari hasil uji yang dilakukan menunjukkan bahwa gim cerita rakyat Bali I Bintang Lara berada pada kategori Baik. Lebih lanjut Uthami menyarankan untuk penelitian serupa agar gim dapat dikembangkan dengan opsi bahasa yang lebih bervariasi dan gameplay yang lebih bervariasi pula agar lebih menarik calon pemain (Uthami et al., 2018).

Penelitian yang dilakukan oleh Pradanita mengembangkan gim edukasi guna mendukung kegiatan pembelajaran pada mata pelajaran desain multimedia. Gim yang dikembangkan oleh Pradanita beraliran role playing game (RPG) dengan metode penelitian Research and Development. Uji coba yang dilakukan oleh Pradanita membagi peserta menjadi dua kelompok yakni kelompok kontrol dan kelompok eksperimen, dimana nantinya Pradanita akan menilai pretest dan posttest dari kelompok kontrol yang tidak mendapat perlakuan khusus dan kelompok eksperimen yang mendapat perlakuan khusus berupa pembelajaran dengan tambahan gim edukasi yang telah dikembangkan. Hasil uji coba menunjukkan bahwa kelas kontrol dan kelas eksperimen mendapat nilai pretest yang sama namun posttest memiliki perbedaan yakni kelompok eksperimen mendapat nilai posttest yang lebih tinggi daripada kelompok kontrol. Hal ini menunjukkan bahwa penerapan gim edukasi dalam kegiatan pembelajaran mempengaruhi hasil belajar berupa peningkatan nilai pada siswa (Pradanita \& Sumbawati, 2017).

Penelitian pengembangan gim RPG yang bertujuan untuk memperkenalkan cerita rakyat telah dilakukan oleh Saputri dan Pratiwi dalam penelitiannya yang berjudul "Pembuatan Game RPG "Roro Jonggrang" Dengan RPG Maker MV". Saputri mengembangkan gim RPG yang mengadopsi ceria rakyat Roro Jonggrang menggunakan RPG Maker MV. Dengan tujuan untuk memperkenalkan cerita rakyat kepada generasi muda yang sudah begitu familiar dengan teknologi sehingga tidak membuat cerita rakyat yang telah diwariskan secara turun temurun hilang begitu saja, Saputri menggunakan model pengembangan Rapid Application Development (RAD) dalam pengembangannya. Kedepannya gim ini masih perlu dikembangkan untuk mengetahui manfaat dari penerapan permainan ini untuk penggunanya (Saputri \& Pratiwi, 2016). 
Penelitian terkait lainnya dilakukan oleh Rahmat dan kawan-kawan, Rahmat mengembangkan gim RPG dengan judul gim "Mari Mengenal Provinsi di Indonesia". Dalam penelitiannya, Rahmat mengembangkan gim menggunakan game engine Unity dengan tujuan memperkenalkan provinsi-provinsi yang ada di Indonesia. Hasil penelitian yang dilakukan oleh Rahmat menunjukkan bahwa gim yang dikembangkan diterima oleh masyarakat luas dan memenuhi hasil yang diinginkan (Kurniawan et al., 2020).

\section{B. Gim (Video Game)}

Gim memiliki makna yakni permainan (Kementrian Pendidikan dan Kebudayaan Republik Indonesia, 2020), menurut adams dalam bukunya, menjelaskan bahwa gim tercipta dari keinginan untuk bermain dan berpura-pura (play and pretending). Keinginan untuk bermain dan berpura-pura tersebut dipadukan dengan elemen peraturan dan elemen tujuan sehingga membentuk sebuah gim (Adams, 2010). Lebih lanjut gim tidak dapat disamakan dengan puzzle karena memainkan gim merupakan aktivitas yang lebih terstruktur. Gim terdiri dari beberapa aliran/genre, yakni(Adams, 2010):

1. Action

2. Strategy

3. Role-playing games

4. Real-world simulations

5. Construction and Management

6. Adventure

Sebuah gim dikatakan sebagai gim yang baik berdasarkan beberapa faktor yang dikategorikan oleh Bond pada jurnalnya, yakni seperti tabel dibawah(Bond \& Beale, 2009):

Tabel 1. Faktor baik dan buruk penentu gim yang baik

\begin{tabular}{ll}
\hline \multicolumn{1}{c}{ Faktor Baik } & \multicolumn{1}{c}{ Faktor Buruk } \\
\hline Gameplay/Mekanik Permainan & Gameplay yang kurang \\
Lingkungan/Atmosfir & Lingkungan/Atmosfir yang kurang \\
Cerita & Penceritaan yang kurang \\
Interaksi Pengguna & Interaksi pengguna yang kurang \\
Kustomisasi & - \\
Fitur Sosial & Fitur sosial yang kurang \\
Variasi & Variasi yang kurang \\
Teknis & Kendala teknis \\
Kohesi & Kurangnya kohesi \\
Pemeliharaan Berkala & - \\
Harga (worth to buy) & Harga (worthless) \\
Franchise & Kegagalan franchise \\
Kuantitas & Kurangnya kuantitas \\
- & Unsur yang mengganggu \\
\hline
\end{tabular}

Lebih spesifik dijelaskan oleh Bond mengenai kriteria yang menentukan faktor-faktor tersebut seperti tabel dibawah (Bond \& Beale, 2009).

Tabel 2. Kriteria sampel per kategori

\begin{tabular}{|c|c|}
\hline Kategori & Kriteria Sampel \\
\hline Gameplay yang baik & $\begin{array}{l}\text { Menarik, adil, seimbang, progresif, menyenangkan, inovatif, mudah dimainkan, sulit } \\
\text { untuk dikuasai, berdasarkan tujuan (objective based), membebaskan pemain, memiliki } \\
\text { unsur paksaan, dinamis, terdapat solusi yang mungkin terjadi }\end{array}$ \\
\hline Lingkungan yang baik & $\begin{array}{l}\text { Berkesan, eye catching, pencayaan yang bagus, efek seperti aslinya, suara yang } \\
\text { bagus, musik yang bagus }\end{array}$ \\
\hline Penceritaan yang baik & $\begin{array}{l}\text { Cerita yang tidak kekanak-kanakan, progresif, tegang, mengasyikkan, dan tertanam } \\
\text { dalam gameplay }\end{array}$ \\
\hline Interaksi pengguna yang baik & $\begin{array}{l}\text { Memberikan umpan balik, dapat dikustomisasi, kontrol tak terlihat, realistis, } \\
\text { fungsional }\end{array}$ \\
\hline Tersedia fitur kustomisasi & Personalisasi yang mudah dilakukan, terdapat fitur modifikasi karakter \\
\hline Interaksi sosial yang baik & Multipemain, kompetisi, komunikasi \\
\hline
\end{tabular}




\begin{tabular}{ll}
\hline \multicolumn{1}{c}{ Kategori } & \multicolumn{1}{c}{ Kriteria Sampel } \\
\hline Bervariasi & $\begin{array}{l}\text { Non linear, pilihan, perbedaan, pertarungan yang dinamis, AI yang bervariasi, } \\
\text { menggunakan taktik, pengemasan media yang bervariasi }\end{array}$ \\
Implementasi teknis yang baik & $\begin{array}{l}\text { Kamera yang baik, tidak ada iklan yang mengganggu, framerate yang halus, } \\
\text { keseragaman, kebebasan berprilaku sesuai harapan } \\
\text { Integrasi yang baik, cerita dan gameplay terkait, cerita yang kohesif, gaya cerita } \\
\text { Kohesi }\end{array}$ \\
yang konsisten \\
Spesifikasi rendah, mudah untuk dipelihara, independen dari perangkat lunak \\
eksternal
\end{tabular}

\section{C. $\quad$ Role Playing Game (RPG)}

Aliran Role Playing Games adalah aliran yang menempatkan pemain seolah-olah merupakan karakter dalam gim tersebut. Ciri utamanya adalah salah satu elemen permainan yang fokus ke arah statistik pertumbuhan satu atau lebih karakter yang diukur menggunakan angka. aliran role-playing games kerap memiliki durasi permainan yang panjang dan identik memiliki depth yang dalam mengingat ia dikemas menjadi cerita yang tampak nyata ditambah dengan fokus pertumbuhan karakter yang menjadi tantangan dalam gim tersebut (Grace, 2005)

\section{Game Development Life Cycle}

Berbeda dengan perangkat lunak, gim yang merupakan perangkat lunak namun bertujuan untuk menghibur pengguna memiliki siklus hidupnya tersendiri, hal ini terjadi karena penerapan SDLC sendiri tidak mampu meliputi setiap elemen dalam gim karena gim bukan produk yang pure engineering, terdapat seni di dalamnya namun bukan juga produk yang pure art, gim merupakan produk multidisiplin yang menggabungkan seni visual, seni audio, programming, dan manajemen (Ramadan \& Widyani, 2013). Hingga kini belum ada model Game Development Life Cycle yang mampu mengembangkan gim yang benar-benar berhasil (Ramadan \& Widyani, 2013), Karena GDLC yang dikembangkan oleh setiap perusahaan dan tim pengembang gim berbeda-beda, Ramadan mengambil setiap karakteristik dari keempat GDLC yang disebutkan sebelumnya menjadi GDLC yang dapat meliputi setiap aspek dalam gim lebih luas dengan diagram sebagai berikut (Ramadan \& Widyani, 2013):

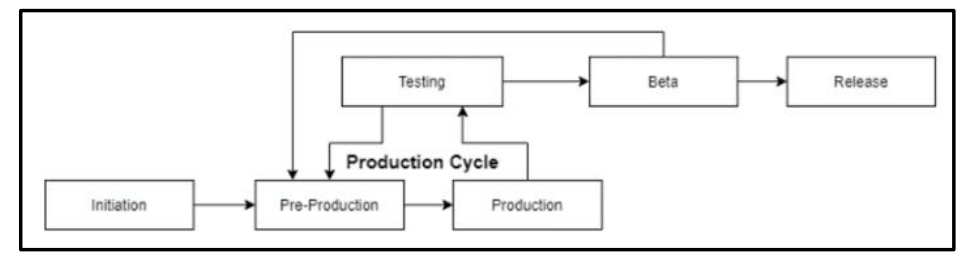

Gambar 1. Model game development life cycle oleh ramadan dan widyani

Model tersebut terdiri dari beberapa tahapan, yakni Initiation, Pre-production, Production, Testing, Beta, Release, dengan penjelasan sebagai berikut (Ramadan \& Widyani, 2013):

1. Initiation

Pada tahap ini tim mendiskusikan konsep kasar dari gim yang akan dikembangkan, pada tahap ini tim umumnya melakukan brainstorming dengan output yakni Game Design Document yang baru berisikan konsep kasar gim dan deskripsi awal gim.

2. Pre-production

Tahap pre-production melibatkan revisi dan penambahan di bagian game design dan membuat prototype. Kemudian Game Design Document diperbaharui berdasarkan hasil uji coba prototype dan revisi di bagian game design. Tahap pre-production ini merupakan fase pertama jika kedepannya terjadi perbaikan atau penambahan fitur dalam gim. Ketika melakukan penambahan fitur/perbaikan fase pembuatan prototype akan dibuat lagi berdasarkan fitur terkait, kemudian versi game design document akan diperbaharui kembali.

3. Production

Tahap production merupakan tahap inti dari pengembangan gim, pada tahap ini semua hal dilakukan dimulai dari membuat asset, programming, dan mengintegrasikannya.

4. Testing 
Tahap testing yang dimaksud adalah tahap alpha-testing, dimana testing dilakukan oleh pihak internal untuk menguji usability dan playability. Jika ditemukan suatu bug atau kerusakan maka akan dibawa kembali ke pre-production untuk mencari jalan keluar dari masalah tersebut.

5. Beta

Tahap beta merupakan tahap ketika gim sudah lulus pengujian internal, kemudian diuji oleh penguji eksternal atau penguji pihak ketiga. Tahap beta terbagi menjadi dua, yakni close beta dan open beta. close beta merupakan tahap dimana pengujian dilakukan oleh pihak eksternal yang diundang saja sedangkan open beta mengizinkan siapapun untuk mendaftar menjadi penguji. Fokus dari tahap beta ini adalah menemukan bug. Jika menemukan bug maka proses pengembangan akan dikembalikan ke preproduction

6. Release

Tahap release adalah tahap dimana gim sudah siap dirilis ke publik.

\section{E. MDA Framework}

MDA adalah pendekatan formal untuk lebih mengerti gim yang dikembangkan oleh tim pengembang. Menjembatani game design dan game development, game criticism dan technical game research. MDA digambarkan seperti gambar berikut(Hunicke et al., 2004):

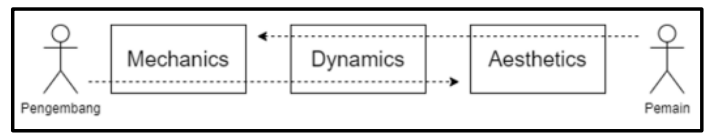

Gambar 2. Bagan MDA framework

Terlepas dari tugas setiap anggota tim yang harus fokus terhadap bidangnya sendiri-sendiri, setiap anggota tim perlu mempertimbangkan hal diluar bidangnya sehingga gim yang dikembangkan tidak mengalami iterasi di fase testing karena gim yang dikembangkan berbeda dengan apa yang sudah direncanakan (Hunicke et al., 2004).

1. Mechanics

Mechanics adalah komponen dalam gim mengenai proses pengolahan data dan algoritma suatu kegiatan (Hunicke et al., 2004). Dalam bahasa sederhana mechanics adalah aturan yang terdapat dalam gim.

2. Dynamics

Dynamics adalah sistem yang mengatur mechanics menjadi sekumpulan aturan dalam gim (Hunicke et al., 2004), seperti contoh mechanic yang membuat karakter berjalan maju adalah tombol "W" terdapat dalam dynamic yang bernama "Player Movement" yang terdiri dari berjalan, melompat, dan lainnya.

3. Aesthtetics

Aesthetics adalah komponen yang melibatkan respons panca indera dari pemain ketika berinteraksi dengan gim. Karena berkaitan dengan respons panca indera pemain, aesthetics erat kaitannya dengan "fun" dalam sebuah gim. Untuk mengenal lebih jauh mengenai "fun" dalam gim, Hunicke mengklasifikasikan aspek "fun" tersebut menjadi 8 aspek (Hunicke et al., 2004). yakni sensastion, fantasy, narrative, challenge, fellowship, discovery, expression, submission.

\section{F. Legenda Desa Trunyan}

Cerita rakyat Legenda Desa Trunyan (Danandjaja, 1989; Hardiningtyas, 2016) Menceritakan tentang perjalanan 4 bersaudara pangeran dan putri Kerajaan Surakarta menuju tanah Bali setelah diutus oleh ayahnya untuk mencari sumber bau harum yang tercium hingga Kerajaan Surakarta. Setelah beberapa minggu perjalanan Putri Keempat Dalem Solo memutuskan untuk menetap karena kelelehan, dengan berat hati perjalanan hanya dilanjutkan oleh Putra Pertama, Kedua dan Ketiga Dalem Solo. Beberapa minggu kemudian, Putra Ketiga dipaksa untuk menetap dan tidak melanjutkan perjalanan karena Putra Ketiga terlena akan keindahan burung yang ditemuinya, Putra Ketiga yang tidak terima pun berdebat dengan Putra Pertama, hingga membuat Putra Pertama kalap dan menendang Putra Ketiga sampai terjatuh metimpuh. Perjalanan kembali dilanjutkan oleh Putra Pertama dan Kedua, sama seperti sebelumnya Putra Kedua kembali dipaksa menetap oleh Putra Pertama karena terlena dengan gadis desa yang menghambat perjalanannya. Setelah berdebat Putra Pertama yang kalap pun menendang putra kedua hingga jatuh melingkuh, kemudian Putra Pertama meninggalkan Putra Kedua di tempat tersebut. Setelah melanjutkan perjalanan lebih jauh, Putra Pertama menemukan sebuah pohon yang bernama Taru Menyan, harumnya sangat mempesona dan bertemu dengan seorang Dewi yang menjaganya, mereka saling jatuh cinta kemudian menikah dan membantun kerajaan Trunyan dengan Putra Pertama Dalem Solo sebagai rajanya dengan gelar Ratu Sakti Pancering Jagat. Kerajaan Trunyan mengalami banyak kesulitan karena pohon Taru 
Menyan menarik hati banyak kerajaan. Akhirnya Ratu Sakti Pancering Jagat pun memutuskan untuk menaruh mayat dibawah pohon tersebut untuk mentralisir bau harum dari pohon tersebut. Akhirnya Kerajaan Trunyan lepas dari permasalahan yang mengganggunya. Kerajaan Trunyan mengalami kemunduran setelah letusan dari gunung Batur.

\section{METODE}

Jenis penelitian yang diterapkan adalah jenis penelitian research and development sesuai dengan definisi dan langkah-langkah yang dipaparkan Sugiyono dengan tahapan-tahapan yakni Potensi dan Masalah; Pengumpulan Data; Desain Produk; Validasi Desain; Revisi Desain; Ujicoba Produk; Revisi Produk; Ujicoba Pemakaian; Revisi Produk; Revisi Masal (Sugiyono, 2013).

Dikarenakan produk yang akan dikembangkan adalah sebuah gim, oleh karena itu langkah-langkah dalam metode penelitian ini akan diasosiasikan pada model pengembangan Game Development Life Cycle yang dikembangkan oleh Ramadan dan Widyani dengan tahapan yakni Initiation, Pre-production, Production, Testing, Beta, dan Release (Ramadan \& Widyani, 2013).

\section{A. Initiation}

Pada tahap initiation akan dilakukan perumusan deskripsi gim dan beberapa detail awal gim seperti judul gim, genre dan topik, goals atau tujuan.

\section{B. Pre-production}

Pada tahap pre-production akan dilakukan perumusan lanjutan detail gim, seperti Penentuan persona, pengumpulan kebutuhan, perumusan core loop, dan rancangan karakter, dilakukan juga perumusan detail lanjutan gim seperti platform, perkiraan ESRB rating, level, dan art style.

\section{Production}

Pada tahap production akan dilakukan proses pembuatan asset pixel art berdasarkan sketsa yang telah dibuat dan mengintegrasikannya dengan Unity. Asset lainnya adalah pengimplementasian storyboard. Lalu mengintegrasikannya ke dalam gim dengan melaksanakan programming.

\section{Testing}

Pada tahap testing, gim yang sudah melewati tahap production akan melewati beberapa uji coba, yakni Uji BlackBox untuk menguji fungsionalitas semua mechanics yang sudah diimplementasikan oleh pengembang itu sendiri, uji ahli isi untuk menguji kesesuaian isi konten gim, dan uji ahli media untuk menguji kelayakan gim secara teknis sebelum memasuki tahap beta. Pengujian ahli isi dan ahli media menggunakan metode penyebaran angket dengan narasumber masing-masing terdiri dari 2 penguji. Data yang didapat akan diolah menggunakan rumus gregory untuk mendapatkan koefisien tingkat validitas sebagai penentu validitas dari gim yang sudah dikembangkan. Perhitungan menggunakan rumus Gregory dimulai dari rekapitulasi menggunakan tabulasi silang sebagai berikut:

Tabel 3. Tabulasi silang dua penilai

\begin{tabular}{cccc}
\hline & & \multicolumn{2}{c}{ Penilai 1 } \\
& & Tidak Sesuai & Sesuai \\
\hline \multirow{2}{*}{ Penilai 2} & Tidak Sesuai & (A) & (C) \\
& Sesuai & (B) & (D) \\
\hline
\end{tabular}

Dengan Keterangan:

$\mathrm{A}=$ = Butir pernyataan dimana kedua penguji sepakat menyatakan tidak sesuai

$\mathrm{B}$ dan $\mathrm{C}=$ Butir pernyataan dimana kedua penguji tidak sepakat

$\mathrm{D}=$ Butir pernyataan dimana kedua penguji sepakat menyatakan sesuai

Perhitungan rumus Gregory_mengikuti perhitungan yang dilakukan oleh Widiartini pada jurnalnya dengan rumus sebagai berikut (Widiartini, 2017):

$$
\text { Koefisien Validitas }=\frac{D}{A+B+C+D}
$$

Kemudian hasil perhitungan menggunakan persamaan (1) dicocokan pada tabel validitas di bawah, untuk menentukan tingkat validitas dari konten gim yang telah dinilai (Widiartini, 2017): 
Tabel 4. Kriteria tingkat validitas uji ahli

\begin{tabular}{lll}
\hline & Nilai Koefisien Validitas & Tingkat Validitas \\
\hline $0,80<$ skor $<1,00$ & Sangat Tinggi & Tinggi \\
$0,60<$ skor $<0,79$ & Cukup \\
$0,40<$ skor $<0,59$ & Rendah \\
$0,20<$ skor $<0,39$ & Sangat Rendah \\
$0,00<$ skor $<0,19$ & \\
\hline
\end{tabular}

\section{E. Beta}

Pada tahap beta, gim akan melewati uji respon pengguna untuk mengetahui respon pengguna, metode pengujian akan menggunakan penyebaran angket dengan peserta merupakan masyarakat Bali yang berumur 13 tahun keatas sesuai dengan perkiraan ESRB Rating yang akan dikenakan pada gim ini yakni 13+. Hasil pengujian akan dihitung menggunakan rumus Likert untuk mendapatkan persentase yang menentukan antusiasme pengguna dalam memainkan gim tersebut. Persentase tanggapan dihitung menggunakan rumus berikut (Abidin \& Purbawanto, 2015):

$$
\text { persentase tanggapan }=\frac{\Sigma \text { skor diperoleh }}{\Sigma \text { skor maksimal }} \times 100 \%
$$

Data hasil jawaban dari (1) harus diinterpretasikan terlebih dahulu dengan menghitung interval jenjang kualitatif, rumus perhitungan interval jenjang kualitatif disebutkan oleh Abidin dan Purwanto (Abidin \& Purbawanto, 2015) dan ditentukan tabel kriteria sebagai berikut:

Tabel 5. Tabel kriteria berdasarkan persentase tanggapan

\begin{tabular}{lll}
\hline & Persentase & Kriteria \\
\hline $84 \%<$ skor $<100 \%$ & & Sangat Baik \\
$68 \%<$ skor $<84 \%$ & Baik \\
$52 \%<$ skor $<68 \%$ & Cukup Baik \\
$36 \%<$ skor $<52 \%$ & Kurang Baik \\
$\%<$ skor $<20 \%$ & Sangat Kurang Baik \\
\hline
\end{tabular}

\section{F. Release}

Tahap release akan dilakukan dengan pendistribusian menggunakan media online dan cakronimam padat (Kaset CD) kepada masyarakat luas dan pihak terkait.

\section{G. Rancangan Dynamics dan Mechanics}

Gim Trunyan akan mengimplementasikan 6 dynamics yang mengatur jalannya permainan, diantaranya adalah sebagai berikut:

1. Main menu dynamics

Dynamics ini mengatur mechanics permainan dalam main menu, seperti mechanics "Lanjutkan Permainan".

2. Cutscene dynamics

Dynamics ini mengatur mechanics permainan ketika sedang menjalankan cutscene, seperti fitur "Lewati Cutscene".

3. Overworld movement dynamics

Dynamics ini mengatur mechanics permainan yang meliputi pergerakan dasar ketika tidak sedang terjadi pertarungan ataupun cutscene.

4. Pause menu dynamics

Dynamics ini mengatur mechanics permainan ketika sedang menjalankan menu jeda.

5. Crafting dynamics

Dynamics ini mengatur mechanics permainan ketika akan menggunakan fitur "racik" untuk meracik item tertentu.

6. Battle dynamics

Dynamics ini mengatur mechanics permainan ketika sedang melakukan pertarungan.

\section{H. Rancangan Aesthetics}

Gim Trunyan akan mengimplementasikan 4 aesthethics, diantaranya adalah sebagai berikut:

1. Sensation 
Pemain yang memainkan gim Trunyan akan disuguhkan pada pixel art style yang ikonis, ambience dan backsound kontemporer yang kental akan nuansa nusantara.

2. Fantasy

Gim Trunyan mengadopsi cerita rakyat Legenda Desa Trunyan yang dipercaya masyarakat. Setiap aksi yang dilakukan akan dirancang sedemikian rupa sehingga pemain akan tergerak untuk berfantasi.

3. Narative

Dramatisasi gim Trunyan, menambah rasa penasaran pemain agar terus melanjutkan permainannya.

4. Challenge

Tantangan dari gim Trunyan adalah, bagaimana pemain dituntut untuk mengatur strategi setiap giliran berdasarkan pergerakan musuh. Pemain juga dituntut untuk memperhatikan statistik dan item yang dimiliki yang harus digunakan sedemikian rupa agar dapat memenangkan pertarungan.

\section{HASIL DAN PEMBAHASAN}

Pengembangan Game RPG 2D Legenda Desa Trunyan yang telah dikembangkan berdasarkan model pengembangan GDLC menghasilkan beberapa hasil dalam setiap tahapannnya yakni sebagai berikut:

\section{A. Hasil Tahap Initation}

1. Deskripsi Gim

Gim Legenda Desa Trunyan adalah gim RPG yang mengadaptasi cerita rakyat Legenda Desa Trunyan menjadi sebuah gim PC yang dapat dimainkan oleh sebagian besar kalangan masyarakat. Petualangan 4 bersaudara pangeran dan putri Kerajaan Dalem Solo ke tanah Bali demi mencari sumber bau harum dari pohon Taru Menyan. Perjalanan tersebut bukanlah perjalanan yang mulus karena tidak ada yang mengetahui siapa yang menunggu di dalam hutan maupun di dalam gua, entah kawan atau lawan kunci utamanya adalah bertahan dan berkembang menghadapi tantangan.

2. Detail Awal Gim

a. Judul Gim

Trunyan

b. Genre dan Topik

$R P G$, Adventure, Mengadaptasi cerita rakyat Legenda Desa Trunyan.

c. Goals/Tujuan

Melakukan petualangan dan mengalahkan musuh yang menghalangi jalan hingga mencapai Pohon Taru Menyan di tanah Bali.

\section{B. Hasil Tahap Pre-production}

1. Pengumpulan Kebutuhan

Survei ketertarikan masyarakat dilaksanakan untuk mengukur animo masyarakat tentang produk penelitian yang akan dikembangkan, dari 127 responden, 125 responden menyatakan tertarik jika Cerita Rakyat Legenda Desa Trunyan diadaptasi ke dalam gim. Lebih spesifik sample responden diambil untuk mendapatkan persona seperti gambar dibawah sebagai pedoman karakteristik calon pemain dari gim yang akan dikembangkan (Chang et al., 2008).

\begin{tabular}{|c|c|c|}
\hline $\begin{array}{l}\text { Umur } \\
\text { Jenis Kelamin } \\
\text { Pekerjaan } \\
\text { Domisili }\end{array}$ & $\begin{array}{l}\text { : } 22 \text { Tahun } \\
\text { : Laki-Laki } \\
\text { : Mahasiswa } \\
\text { : Karangasem, Bali }\end{array}$ & \\
\hline \multicolumn{3}{|c|}{$\begin{array}{ll}\text { Motivasi Bermain Gim } & \text { : Sarana hiburan dan hobby } \\
\text { Kebiasaan Bermain Gim } & \text { : Bermain } 3-4 \text { jam menggunakan PC } \\
\text { Sumber Frustasi Ketika Bermain Gim } & \text { : Gim Pay to Win, cheater } \\
\text { Kebiasaan Mencari Info Tentang Gim } & \text { : Via youtube } \\
\text { Kebiasaan Belanja Gim } & \text { : Ketika diskon, yang kuat di PC } \\
\text { Kriteria Dalam memilih Gim } & \text { : RPG, Adventure, ceritanya bagus } \\
\text { Kebiasaan di Luar Gim yang Relevan dengan Gim } & \text { : Diskusi dengan teman tentang gim }\end{array}$} \\
\hline
\end{tabular}

Gambar 3. Sampel user persona

2. Detail Lanjutan Gim
a. Platform
$P C$, sistem operasi Windows
b. Perkiraan ESRB rating
Teen $(13+)$ 
c. Level

7 Chapter, 8 Dungeon, 12 Cutscene

d. Art Style

$2 D$ Pixel art

3. Core Loop

Core loop dari gim Trunyan terdiri dari 3 tahap yakni masuk dungeon untuk melakukan battle atau pertarungan, kemudian melanjutkan cerita seperti pada gambar dibawah.

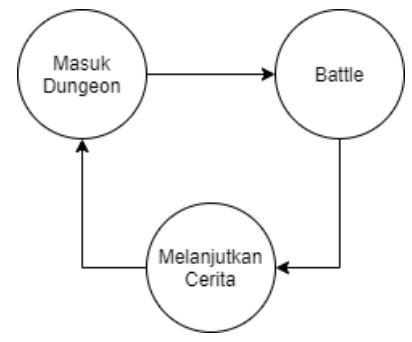

Gambar 4. Core loop dari gim trunyan

4. Rancangan Karakter

Rancangan karakter merupakan sketsa kasar dari desain karakter yang akan diimplementasikan dalam dan akan disesuaikan dengan jenis art style yang akan digunakan dalam gim. Rancangan karakter dari gim Trunyan adalah sebagai berikut:
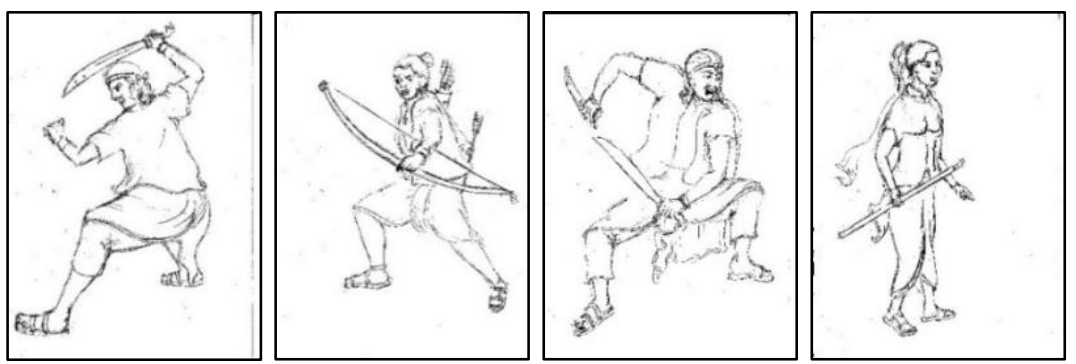

Gambar 5. (Kiri ke kanan) putra pertama, kedua, ketiga, dan putri keempat dalem solo
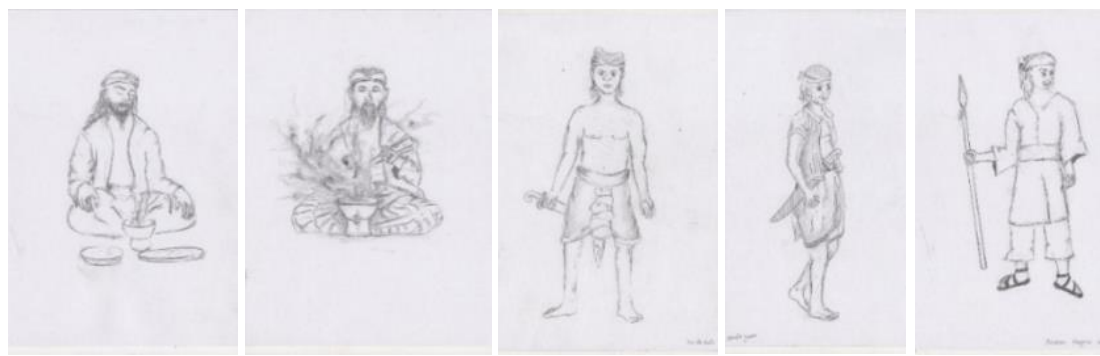

Gambar 6. (Kiri ke kanan) balian, guru balian, penyamun, raja penyamun, dan prajurit

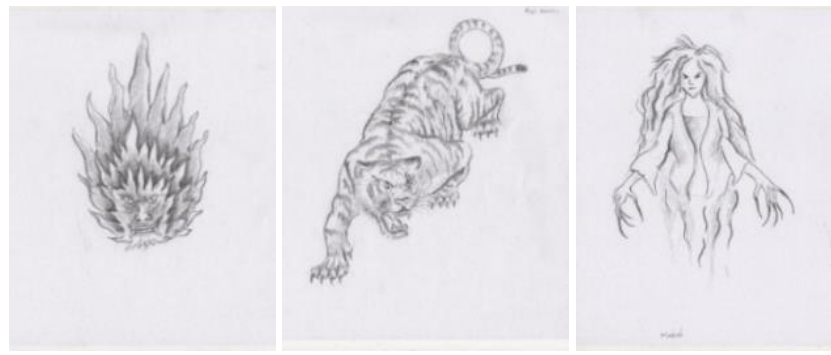

Gambar 7. (Kiri ke kanan) endih, siluman harimau, dan memedi 


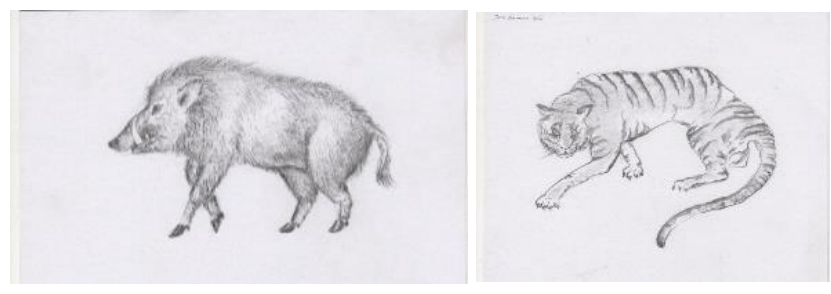

Gambar 8. (Kiri ke kanan) babi hutan dan harimau

\section{Hasil Tahap Production}

1. Pembuatan Pixel Art

Proses pembuatan pixel art menggunakan aplikasi Piskel versi 0.14.0, dengan referensi karakter berasal dari sketsa karakter yang telah dirancang sebelumnya dengan beberapa improvisasi. Menganimasikan pixel art menggunakan sistem frame-by-frame yang dibuat di aplikasi yang sama, berikut adalah hasil pembuatan pixel art 4 tokoh utama.

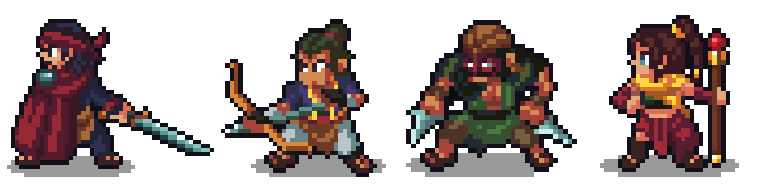

Gambar 9. (Kiri ke kanan) pixel art putra pertama, kedua, ketiga, dan putri keempat dalem solo

2. Perancangan Antarmuka

Perancangan tampilan antarmuka dilakukan langsung dalam unity dengan hanya mengkombinasikan komponen-komponen untuk antarmuka yang ada seperti image, canvas, button, outline, dan shadow. Berikut adalah hasil perancangan antarmuka menu utama

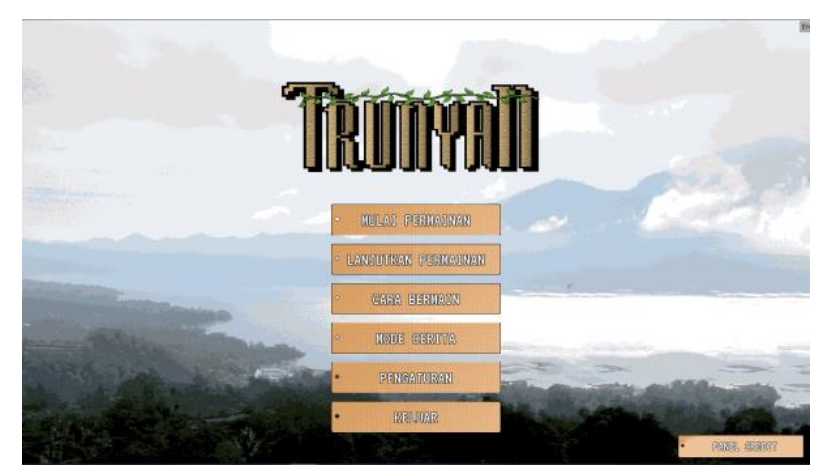

Gambar 10. Contoh hasil perancangan antarmuka

3. Perancangan Dungeon

Proses pembuatan dungeon dilakukan dengan menggambar "gambaran kasar" pada kertas agar lebih mudah menentukan zona pertarungan, titik masuk, titik keluar, titik dialog dan titik quest/tujuan. Kemudian hasil gambar dijiplak ke dalam Unity dengan tilemap dan collision. Berikut adalah hasil perancangan desain untuk dungeon stage 1

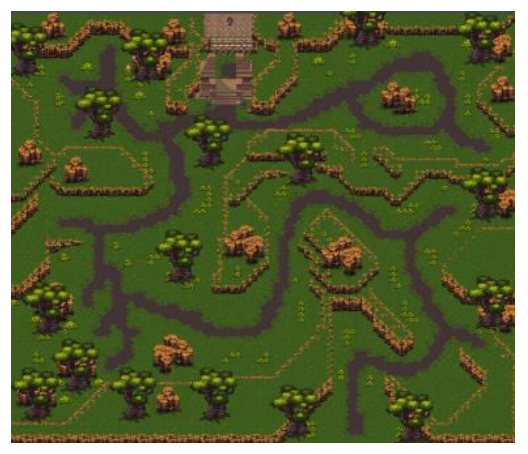

Gambar 11. Contoh hasil perancangan dungeon 
4. Pembuatan Cutscene

Cutscene dibuat berdasarkan referensi dari storyboard dan sketsa karakter yang sudah dirancang sebelumnya, cutscene dibuat menggunakan aplikasi Sketchbook, berikut adalah hasil pembuatan cutscene 1 .

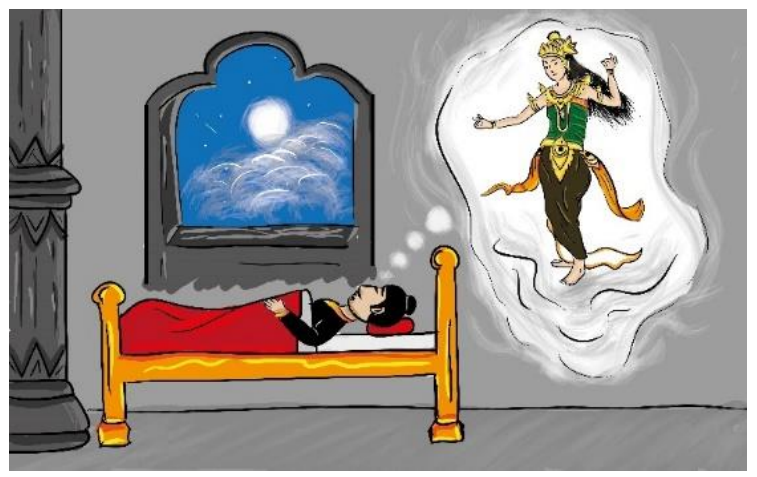

Gambar 12. Contoh perancangan cutscene 1

\section{Hasil Tahap Testing}

1. Hasil Pengujian BlackBox

Pengujian BlackBox menguji 66 poin fitur yang telah dikembangkan, hasil pengujian menyatakan semua fitur telah berjalan dengan baik dari pihak internal pengembang.

2. Hasil Pengujian Ahli Isi

Pengujian ahli isi dilakukan oleh 2 narasumber, yakni I Wayan Besar selaku Kepala Dusun Banjar Madia Desa Trunyan, dan I Nengah Putra selaku Kelian Adat Banjar Madia. Rekapitulasi pengujian ahli isi dimuat dalam tabel berikut:

Tabel 6. Rekapitulasi pengujian ahli isi

\begin{tabular}{cccc}
\hline & & \multicolumn{2}{c}{ Penilai 1 (I Wayan Besar) } \\
& & Tidak Sesuai & Sesuai \\
\hline \multirow{2}{*}{ Penilai 2 (I Nengah Putra) } & Tidak Sesuai & (A) - & (C) - \\
& Sesuai & (B) - & (D) $1,2,3,4,5,6$ \\
\hline
\end{tabular}

Rekapitulasi angket pengujian ahli isi diolah lebih lanjut untuk menentukan koefisien validitas dengan perhitungan sebagai berikut

$$
\text { Koefisien Validitas }=\frac{D}{A+B+C+D}=\frac{6}{6}=1.00
$$

Berdasarkan perhitungan (2), nilai koefisien validitas yang didapatkan adalah 1.00 sehingga termasuk dalam kategori tingkat validitas sangat tinggi.

3. Hasil Pengujian Ahli Media

Pengujian ahli isi dilakukan oleh 2 narasumber, yakni I Putu Kusuma Putra, S.Pd selaku Game Developer dari Devata Games, dan Kriswin Yuniar selaku Game Artist dari Tahoe Games Rekapitulasi pengujian ahli media dimuat dalam tabel berikut

Tabel 7. Rekapitulasi Pengujian Ahli Media

\begin{tabular}{cccc}
\hline & & \multicolumn{2}{c}{ Penilai 1 (I Putu Kusuma Putra, S.Pd) } \\
& & Tidak Sesuai & Sesuai \\
\hline \multirow{2}{*}{ Penilai 2 (Kriswin Yuniar) } & Tidak Sesuai & (A) - & (C) - \\
& Sesuai & (B) - & (D) $1,2,3,4,5,6,7,8,9,10$ \\
\hline
\end{tabular}

Rekapitulasi angket pengujian ahli media diolah lebih lanjut untuk menentukan koefisien validitas dengan perhitungan sebagai berikut.

$$
\text { Koefisien Validitas }=\frac{D}{A+B+C+D}=\frac{10}{10}=1.00
$$


Berdasarkan perhitungan (3), nilai koefisien validitas yang didapatkan adalah 1.00 sehingga termasuk dalam kategori tingkat validitas sangat tinggi.

\section{E. Hasil Tahap Beta}

Pada tahap beta dilakukan uji respon pengguna dengan jumlah peserta sebanyak 31 orang, dengan total skor yang diperoleh berjumlah 2153 dari total skor maksimal yakni 2353. Pengolahan uji respon pengguna dilakukan dengan menghitung persentase tanggapan dengan rumus sebagai berikut:

$$
\begin{aligned}
& \text { persentase tang gapan }=\frac{\Sigma \text { skor diperoleh }}{\Sigma \text { skor maksimal }} \times 100 \% \\
& \text { persentase tanggapan }=\frac{2153}{2353} \times 100 \% \\
& \text { persentase tanggapan }=0,926 \times 100 \% \\
& \text { persentase tanggapan }=93 \%
\end{aligned}
$$

Berdasarkan hasil perhitungan (7), dengan persentase tanggapan sebesar 93\%, gim Trunyan termasuk ke dalam kategori "Sangat Baik".

\section{F. Hasil Tahap Release}

Project yang sudah berhasil di-build sudah siap dimainkan oleh masyarakat luas, pengembangan akan dihentikan di titik ini. Namun dalam beberapa kasus tidak menutup kemungkinan akan dilakukan beberapa perbaikan sehingga kualitas gim dapat lebih baik lagi.

\section{G. Pembahasan}

Kurangnya media pelestarian budaya khususnya pelestarian cerita rakyat Legenda Desa Trunyan yang interaktif dan dapat dimainkan kapan saja dan dimana saja tanpa mengeluarkan biaya tambahan emngantarkan pengembangan media gim sebagai solusi dari permasalahan tersebut.

Pengembangan gim Trunyan mengikuti kaidah metode Penelitian dan Pengembangan model Game Development Life Cycle dengan beberapa tahapan yakni tahap Initiation, Pre-production, Production, Testing, Beta, dan Release.

Sebelum gim disebarkan ke masyarakat luas, terlebih dahulu dilakukan pengujian ahli isi untuk menguji kesesuaian isi konten dalam gim dan pengujian ahli media untuk menguji kelayakan gim secara teknis. Pengujian ahli isi dilakukan oleh I Wayan Besar dan I Nengah Putra selaku penduduk asli Desa Trunyan dan pengujian ahli media dilakukan oleh I Putu Kusuma Putra, S.Pd dan Kriswin Yuniar selaku praktisi Game Developer dari studio masing-masing. Kedua hasil pengujian mendapatkan koefisien validitas sebesar 1.00 dan termasuk dalam kategori validitas sangat tinggi.

Selanjutnya dilakukan uji respons pengguna untuk menguji kepuasan pemain dan ketepatan gim dengan aspek aesthetics yang dirancang. Secara keseluruhan uji respon pengguna mendapatkan hasil 93\% dan termasuk dalam kategori Sangat Baik. Angket uji respon pengguna ini disusun berdasarkan pendapat Bond pada jurnalnya yang mengatakan bahwa desain sebuah gim yang bagus memiliki beberapa elemen seperti kohesi, variasi, interaksi pengguna yang baik, dan beberapa interaksi sosial yang baik, serta menghindari faktor terpenting yakni harga yang buruk (Bond \& Beale, 2009), dengan persentase yang didapatkan maka gim Trunyan dapat dinyatakan sebagai gim yang baik.

\section{SIMPULAN DAN SARAN}

Dari penelitian yang telah dilakukan, dapat disimpulkan beberapa hal sebagai berikut Pengembangan gim Trunyan dilakukan dengan menggunakan model GDLC dengan tahapan yakni initation, pre-production, production, testing, beta. Sebelum mengetahui respon pengguna, dilakukan pengujian oleh ahli isi dan ahli media terlebih dahulu. Pengujian oleh ahli isi melibatkan 6 poin pernyataan dan menghasilkan nilai koefisien validitas sebesar 1.00 yang termasuk dalam kategori "sangat baik", pengujian oleh ahli media melibatkan 10 poin pernyataan dan menghasilkan nilai koefisien validitas sebesar 1.00 yang termasuk dalam kategori "sangat baik" pula. Oleh karena itu dapat disimpulkan bahwa gim Trunyan sudah layak untuk dimainkan oleh pihak eksternal dan siap dilanjutkan untuk mengetahui uji respon pengguna. Pengujian respon pengguna melibatkan 31 responden yang menjawab 15 butir pernyataan angket uji respon pengguna. Hasil akhir persentase total mendapat nilai sebesar $93 \%$ dan termasuk dalam kategori "sangat baik".

Gim Trunyan yang telah dikembangkan masih belum sempurna jika dibandingkan dengan gim RPG yang lebih kompleks dan sukses di pasarnya, gim Trunyan masih memiliki elemen yang perlu dikembangkan lebih dalam dari segi mechanics, dynamics, aesthetics. Kedepannya diharapkan agar Cerita 
yang diadopsi lebih bervariatif sehingga tidak hanya cerita rakyat Legenda Desa Trunyan yang dilestarikan. Namun cerita rakyat lainnya juga dilestarikan agar tidak dilupakan seiring berkembangnya zaman. Kemudian Mechanics, dynamics, aesthetics dirancang agar lebih kompleks dan lebih luas sesuai dengan formula gim RPG yang telah sukses di pasarnya, selain itu Perancangan collision yang lebih diperhatikan agar tidak membuat pemain terjebak tidak bisa bergerak dalam permainan dan yang terakhir Perancangan framerate animasi yang terstruktur sehingga kecepatan gerakan menjadi seragam.

\section{Daftar Pustaka}

Abidin, Z., \& Purbawanto, S. (2015). Pemahaman Siswa Terhadap Pemanfaatan Media Pembelajaran Berbasis Livewire Pada Mata Pelajaran Teknik Listrik Kelas X Jurusan Audio Video Di Smk Negeri 4 Semarang. Edu Elektrika Journal, 4(1), 38-49.

Adams, E. (2010). Fundementals of Game Design. In K. Johnson, R. Thomas, C. Borman, R. Rider, \& C. Weaver (Ed.), Pearson Prentice Hall $(2$ ed.). Pearson Education, Inc. http://wps.prenhall.com/bp_gamedev_1/54/14053/3597646.cw/index.html

APJII. (2020). Laporan Survei Internet APJII 2019 - 2020. Asosiasi Penyelenggara Jasa Internet Indonesia, 2020, 1-146. https://apjii.or.id/survei

Asmawati, E., Maskun, \& Basri, M. (2017). Hubungan Gaya Belajar Kinestetik Dengan Efektivitas Belajar Sejarah Siswa Kelas X. PESAGI (Jurnal Pendidikan dan Penelitian Sejarah), 5(7), 1-12. http://jurnal.fkip.unila.ac.id/index.php/PES/article/view/13641

Bond, M., \& Beale, R. (2009). What makes a good game? Using reviews to inform design. People and Computers XXIII Celebrating People and Technology - Proceedings of HCI 2009, April, 418-422. https://doi.org/10.14236/ewic/hci2009.52

C, F. F., \& Akbarsyah, A. (2013). Role Playing Game ( Rpg ) “Legenda Ular K Epala Tujuh ” Dengan Editor Rpg Maker Vx.

Chang, Y. N., Lim, Y. K., \& Stolterman, E. (2008). Personas: From theory to practices. ACM International Conference Proceeding Series, 358(August 2015), 439-442. https://doi.org/10.1145/1463160.1463214

Danandjaja, J. (1989). Kebudayaan Petani Desa Trunyan Bali: Lukisan Analitis yang Menghubungkan Praktek Pengasuhan Anak Orang Trunyan dengan Latar Belakang Etnografisnya. PT. Dunia Pustaka Jaya.

Eldiana, N. frisda, \& Muliawati, N. eka. (2019). Pengembangan Game "COC" RPG Maker MV Sebagai Media Pembelajaran Pada Materi KPK. APOTEMA : Jurnal Program Studi Pendidikan Matematika, 2(5), 150161. https://doi.org/10.31597/ja.v2i5.740

Grace, L. (2005). Game Type and Game Genre.

Gusal. La Ode. (2015). Nilai-Nilai Pendidikan dalam Cerita Rakyat Sulawesi Tenggara Karya La Ode Sidu. Jurnal Humanika, 15(3), 1-18. http://ojs.uho.ac.id/index.php/HUMANIKA/article/view/611

Hardiningtyas, P. R. (2016). Bau Wangi Taru Menyan (R. A. Ekoputranti (ed.)). Badan Pengembangan dan Pembinaan Bahasa.

Hunicke, R., Leblanc, M., \& Zubek, R. (2004). MDA: A formal approach to game design and game research. AAAI Workshop - Technical Report, WS-04-04(January 2004), 1-5. https://www.researchgate.net/publication/228884866_MDA_A_Formal_Approach_to_Game_Design _and_Game_Research

Kementrian Pendidikan dan Kebudayaan Republik Indonesia. (2020). gim. Kamus Besar Bahasa Indonesia Daring. https://kbbi.kemdikbud.go.id/entri/gim

Kotaniartha, I. W., \& Wijayanti, A. (2019). MAKNA PESAN MORAL LIRIK LAGU TRADISIONAL BALI (SEKAR ALIT) DALAM MEMBENTUK KARAKTER ANAK. Seminar Nasional INOBALI 2019, 1177-1185.

Kurniawan, R., Assegaff, S., \& Rohaini, E. (2020). Perancangan Game Rpg “ Mari Mengenal Provinsi Di Indonesia " Menggunakan Unity. Jurnal Ilmiah Mahasiswa Teknik Informatika, 2(1), 13-30. http://ejournal.stikom-db.ac.id/index.php/jimti/article/view/802

Meolbatak, E. M., Amfotis, P. D., \& Bone, M. P. (2018). Pembuatan Game Budaya Dawan Berbasis Multimedia. Konferensi Nasional Sistem Informasi, 1201-1206.

Pradanita, W. R., \& Sumbawati, M. S. (2017). Pengembangan Game Edukasi Bertipe Role Playing Game (RPG) pada Mata Pelajaran Desain Multimedia di SMK Negeri 1 Jombang. It-Edu, 2(02), 263-272. https://jurnalmahasiswa.unesa.ac.id/index.php/it-edu/article/view/22747/20856

Ramadan, R., \& Widyani, Y. (2013). Game Development Life Cycle Guidelines. 2013 International Conference 
98 INSERT: Information System and Emerging Technology Journal. Vol. 2, No. 2, Desember 2021

on Advanced Computer Science and Information Systems, ICACSIS 2013, September 2013, 95-100. https://doi.org/10.1109/ICACSIS.2013.6761558

Sanjaya, D. P. A., Purnawan, I. K. A., \& Rusjayanthi, N. K. D. (2016). Pengenalan Tradisi Budaya Bali melalui Aplikasi Game Explore Bali Berbasis Android. Lontar Komputer: Jurnal Ilmiah Teknologi Informasi, 7(3), 162-173. https://doi.org/10.24843/lkjiti.2016.v07.i03.p04

Saputri, F. H., \& Pratiwi, D. (2016). Pembuatan Game RPG “Roro Jonggrang” Dengan RPG Maker MV. Seminar Nasional Cendekiawan, 9.1-9.9.

Sugiyono. (2013). Metode Penelitian Kuantitatif, Kualitatif, dan Tindakan. Penerbit Alfabeta.

Uthami, A. A. I. P., Arthana, I. K. R., \& Sindu, I. G. P. (2018). Pengembangan Game Cerita Rakyat Bali I Bintang Lara Berbasis Android. Kumpulan Artikel Mahasiswa Pendidikan Teknik Informatika (KARMAPATI), 7(2), 113-126. https://doi.org/10.23887/karmapati.v7i2.15280

Widiartini, N. K. (2017). Uji validitas instrumen pengukuran kualitas modifikasi motif dan bahan pada kain tenun mastuli. Seminar Nasional Riset Inovatif 2017, 530-535. https://eproceeding.undiksha.ac.id/index.php/senari/article/download/1075/799 